$3{ }^{1}$ PhD student, Division of Civil Engineering, Department of Engineering, University of

4 Cambridge, ISG-62, Trumpington Street, Cambridge, CB2 1PZ, UK (corresponding author). E-

5 mail: scr58@cam.ac.uk

$6 \quad{ }^{2}$ Laing O'Rourke Lecturer of Construction Engineering, Department of Engineering, University

7 of Cambridge, BC2-07, Trumpington Street, Cambridge, CB2 1PZ, UK. Email:

8 ib340@cam.ac.uk

\title{
9 Abstract:
}

10 The World Bank reports that pavement networks carry more than $80 \%$ of a country's total

11 passenger-km and over 50\% of freight ton-km, justifying the importance of efficiently

12 maintaining pavements. Knowing the pavement condition is essential for efficiently deciding on

13 maintenance programs. Current practice is predominantly manual with only $0.4 \%$ of inspections

14 happening automatically. All methods in the literature aiming at automating condition

15 assessment focus on two defects at most, or are too expensive for practical application. In this

16 paper, we propose a low-cost method that automatically detects pavement defects simultaneously

17 using parking camera video data. The types of defects addressed in this paper are two types of

18 cracks, longitudinal and transverse, patches and potholes. The method uses the Semantic Texton

19 Forests (STFs) algorithm as a supervised classifier on a calibrated region of interest (myROI),

20 which is the area of the video frame depicting only the usable part of the pavement lane. It is

21 validated using data collected from the local streets of Cambridge, UK. Based on the results of

22 multiple experiments, the overall accuracy of the method is above $82 \%$, with a precision of over 
$2391 \%$ for longitudinal cracks, over $81 \%$ for transverse cracks, over $88 \%$ for patches and over $76 \%$

24 for potholes. The duration for training and classifying spans from 25 minutes to 150 minutes,

25 depending on the number of video frames used for each experiment. The contribution of this

26 paper is dual: 1) an automated method for detecting several pavement defects at the same time,

27 and 2) a method for calculating the region of interest within a video frame considering pavement

28 manual guidelines.

29 Keywords: pavement assessment; pavement defect; automated detection;

\section{INTRODUCTION}

31 The US Society of Civil Engineers and the UK Institution of Civil Engineers have each graded

32 their country's respective pavement infrastructure with a D, emphasizing the poor condition of

33 existing pavements (ASCE 2013; ICE 2014). A survey held in the UK regarding the country's

34 infrastructure showed that $52 \%$ of UK businesses reported a deterioration of highways, and $77 \%$

35 expect the same trend for the near future (CBI and URS 2014). More than $85 \%$ of respondents

36 believe that the bad quality of pavements is a consequence of the current maintenance

37 procedures. A similar survey held two years earlier revealed that this is a concern for the

38 citizens as well, as $43 \%$ identify the urgency of revising the currently-followed maintenance

39 process (Audit Commission 2011).

40 Pavement condition assessment is a prerequisite for efficiently designing, planning and

41 deciding on maintenance programs. The initial requirements for an asset management system is

42 to be aware of the existing assets, their status and the level of service they provide (NAMS

43 Group 2006). The Department of Transport and Highways Agency in the UK report that current

44 pavement condition data is insufficient and gaps exist in the collected information (National

45 Audit Office 2014). Figure 1 shows a depiction of the current practice. The colored background 
46 boxes include the name of each step of the process. The white colored background boxes

47 include the way that each method is performed, either automatically or manually. The steps of

48 defect identification and assessment are mainly manual, however some road authorities own

49 software for automatically detecting and assessing cracks.

50 The aim of the process is to capture the longitudinal and transverse profiles of the

51 pavement, the condition at its edges, and the texture of the surface. At first, inspectors are

52 collecting raw data either automatically or manually. Automated data collection uses specialized

53 vehicles that are mounted with laser scanners, pavement profilers, accelerometers, image and

54 video cameras, and positioning systems (DfT 2011). Several US states own such vehicles for 55 automatically detecting pavement data (Attoh-Okine and Adarkwa 2013; Liosatos 2013; Rami

56 and Kim 2015; Richardson et al. 2015; Rick Miller 2015; Zhou et al. 2013). The number and

57 type of sensors on those vehicles determine their purchase cost, which usually starts at

58 approximately $£ 500,000$ (Werro 2013). The choice of sensors also drives the operational costs,

59 which is between $£ 20$ and $£ 40$ per kilometer. Due to these high costs, the use of automated data

60 collection is restricted to the primary pavement network and only once per year (MnDOT 2009).

61 In the case of the UK, the primary road network constitutes almost $20 \%$ (major and ' $\mathrm{B}$ '

62 roads correspond to 50,200 miles out of 245,800 (DfT 2015)) of the total pavement length.

63 Inspectors are driving the primary network, for inspection purposes every week of the year.

64 Hence, 52 times a year the primary network is inspected manually. In addition, automated

65 inspection is applied on that part of the network only once a year. The above translates into $98 \%$

$66(52 / 53)$ of manual inspection and 2\% (1/53) of automated inspection. As for the rest of the

67 network, it is only inspected manually. So: a) Volume of manual inspection $=80 \%+20 \% * 98 \%$

$68=99.6 \%$, and b) Volume of automated inspection $=100-99.6=0.4 \%$ 
Accredited surveyors who either walk or drive (Dye Management Group, Inc 2015;

70 PublicWorksTraining 2014; Rami and Kim 2015; UKPMS 2005) along the road perform the

71 other $99.6 \%$ of inspections. Inspectors insert all gathered data into the road authority's central

72 database at the end of each inspection session. Such data includes images and descriptions of

73 road defects encountered. "Before and after" images are required for repairs conducted on the

74 spot along with a description of actions taken. The inspector is responsible for assigning a

75 priority rating for repair based on the level of the defect's severity, in case he/she cannot address

76 the defect on the spot. Hence, the second and third steps of the assessment process happen at the

77 same time when collecting data manually. Manual visual surveys are time consuming, laborious

78 and inefficient considering the amount of network that inspectors need to cover, in conjunction

79 with the multiple tasks that he/she has to perform.

80 Technicians perform the second and third steps of the process for data collected using

81 automated methods. Multiple screens are used to project video, images, and other sensor data in

82 order for technicians to identify the defective areas and assess their level of severity (FHWA

83 2003; McTavish 2012; MnDOT 2009; Zhou et al. 2013). Image and camera data is mainly used

84 as visual aid material to assist in the defect identification and assessment. The subjectivity of the

85 technician inevitably affects the assessment results based on the level of his/her experience,

86 even if well-written and reliable manuals are utilized during the assessment (Bianchini et al.

87 2010). It is also nearly impossible to analyze the vast amounts of collected data, so only $10 \%$ is

88 typically post-processed (MnDOT 2003).

89 We conclude that the current pavement condition monitoring process is laborious, time

90 consuming and subjective based on the limitations identified above. Hence, the aim of this paper

91 is to present a method that is free of such limitations. The contributions of this paper are: 1) an 
92 automated method for simultaneously detecting longitudinal and transverse cracks, potholes and

93 patches, and 2) a method for calculating the region of interest within a video frame taking into

94 consideration the sizes of defects that inspectors are looking for according to pavement

95 inspection manuals. The following section presents the current state of research for automated

96 defect detection. The same section also discusses methods that are useful to this paper's research

97 objective. Section 3 details the proposed method for automatically detecting pavement defects

98 simultaneously. Section 4 discusses the implementation process and the results from the

99 validation of the proposed method. Finally, section 5 includes the conclusions derived from this

100 piece of research along with a discussion regarding future work.

\section{BACKGROUND}

\section{Research on pavement defect detection}

103 Research has focused on automating the detection of pavement defects, in order to overcome the

104 limitations of the current practice. Figure 2 depicts the relevant current research in a three-

105 dimensional graph and table 1 provides a list of all relevant references. The papers found in the

106 literature are categorized using three criteria: 1) type of defect (x-axis), 2) type of data used for

107 analysis (y-axis), and 3) level of detail reached (z-axis). The subcategories of the z-axis are

108 presence, detection, and measurement. Presence is the sub-category that includes methods,

109 which answer the simple question of whether a defect exists in the given data or not. Detection

110 is the sub-category of methods that identify the exact position of the defect within the data.

111 Finally, measurement includes methods that are capable of providing the spatial measurements

112 of the detected defect, such as the width and depth of a pothole. 
114 differentiating images that depict pavement defects from those that do not. Several methods that

115 focus on cracks have been proposed in the literature. Some have focused on offline or real-time

116 crack detection. Efforts have been made for classifying the different crack types, such as

117 alligator, longitudinal or transverse. Methods were also developed for estimating the depth of a

118 pavement crack, and for automatically sealing them. A comparison study concluded that none

119 are comprehensive and robust. 2D image-based methods that focus on other defects, such as

120 patches and potholes also exist in the literature.

121 Other methods based on 2D images use stereo vision to reconstruct the captured scene.

122 Researchers initially tested this idea in the area of pavement reconstruction, and used it later to

123 detect highway assets (Balali and Golparvar-Fard 2015; Uslu et al. 2011) such as guardrails and

124 pavement markings. This method, although accurate, does not concentrate on pavement defects.

125 Some researchers have used 3D reconstruction for understanding the pavement surface's texture

126 and for measuring the depth of potholes to calculate the necessary filling material. Others have

127 applied it for the purpose of detecting and classifying cracks or for calculating the crack depth

128 (Yu et al. 2007).

129 Spatial data methods utilize range sensors to detect elevation defects such as rutting and 130 shoving. These defects are not detectable in standalone images. The advantages of those methods

131 are: 1) they are not disruptive, since the vehicle that carries the necessary equipment and

132 performs the data collection can travel up to $100 \mathrm{~km} / \mathrm{hr}$, and 2) they are insensitive to lighting

133 conditions, which allows their application at any time of the day. These sensors are quite

134 expensive though, which restricts their extensive/regular use in practice. 
136 of the pavement surface or estimating the pavement profile. An accelerometer is such a sensor

137 and its advantage is the small storage it requires for saving the collected data, which allows easy

138 real-time processing. However, it is necessary to calibrate the vehicle with the sensors so the

139 results are possible to compare.

140 In summary, no method addresses all, or even most, pavement defects simultaneously, as

141 shown in the research cube by the empty "all defects" column. Such methods are necessary in

142 order to address the limitations of current practice. Methods that focus on one or a few defects

143 are appealing, but still require the manual detection of the rest. In other words, unless a method

144 that automatically detects all types of defects at the same time is used, inspectors would need to

145 assess the network manually. Having inspectors perform their job for some defects, while other

146 are detected automatically invalidates the practical use of the method for cost reasons. Hence,

147 current practice limitations remain.

\section{Machine learning for object detection}

149 Machine learning multi-classifier algorithms enable the simultaneous segmentation and

150 recognition of several objects in images (Shotton et al. 2009; Uijlings et al. 2010; Zhang 2000).

151 There are three different categories of such algorithms, and those are supervised, semi-

152 supervised and unsupervised. Supervised are the algorithms that use multiple manually annotated

153 data/images to train themselves how to detect certain patterns. Training images typically depict

154 several poses of the object(s) in interest, to cover all possible appearances. Such algorithms

155 create a codebook of visual words during training, and each word corresponds to a region of the

156 image. This is achieved with the extraction of feature descriptors using algorithms such as SIFT 
157 (Scale Invariant Feature Transform) (Lowe 2004) and SURF (Speed-Up Robust Features) (Bay 158 et al. 2008).

159 During road condition assessment the aim is to identify road defects and distinguish them

160 from each other. Thus, both the input and the output are known in advance. Road data is easy to

161 find and collect, so there is no need to engage unsupervised training, which is usually meant for

162 cases where data is insufficient or difficult to obtain. Another parameter of categorizing learning

163 algorithms is by considering the way they are operating. This is with respect to whether they

164 make a generalization based on the training data and build a rule for classifying new data, or

165 whether they use all of the training data for every classification decision. The former is the so-

166 called eager learning, whereas the latter is named lazy learning. Lazy learning techniques require

167 a large storage space and are quite slow while classifying data, and thus are not selected for the 168 purpose of this paper.

169 Artificial Neural Networks (ANNs) are a widely used family of classification algorithms

170 (Zhang 2000) and are based on the notion of perceptrons, consisting of a large number of units

171 (neurons) connected in different patterns. Researchers have used ANN methods for road

172 condition related problems such as crack detection (Wu et al. 2016; Xu et al. 2008), defects and

173 road roughness reconstruction (Ngwangwa et al. 2010) and road profile estimation (Solhmirzaei

174 et al. 2012). The main disadvantages of the ANN methods are: 1) they are quite slow and require

175 much time for training, 2) designing the hidden layer and its nodes is difficult because an

176 underestimate in the number of neurons can lead to poor results (Kotsiantis et al. 2007), and 3)

177 they underperform in noisy data.

178 Support Vector Machines (SVM) is another supervised classification method. The main 179 idea of SVMs is to construct a set of hyperplanes for classifying data based on their distance 
180 from them (Wu et al. 2008). Usually, a range of potential settings are tested and cross validated

181 to identify the best option in each problem. For that reason, SVMs have low speed in the training

182 phase (Kotsiantis et al. 2007). On the other hand, the complexity of the model is unaffected from

183 the number of features selected for the training phase and this constitutes a benefit of the method.

184 They are very popular for binary classifications. However, they do not seem suitable for the

185 classification of multiple defects.

186 Superpixel algorithms are quite popular recently within the computer vision community

187 for image segmentation applications. Such algorithms segment images into groups of pixels that

188 are meaningful atomic regions. Many approaches exist in the literature (Felzenszwalb and

189 Huttenlocher 2004; Levinshtein et al. 2009; Veksler et al. 2010), each one with its own

190 advantages and limitations, and the characteristics of each application define which one is the

191 best to be applied. However, some considerations/limitations that affect the quality of a

192 superpixel algorithm are the following: 1) many parameters need to be tuned, which can result in

193 lost time and poor performance, 2) providing the option to specify the amount of superpixels,

194 which isn't a characteristic of all such algorithms, and 3) providing the ability to control the

195 compactness (compactness refers to a regular shape and size of the superpixels along with

196 smooth boundaries (Schick et al. 2012)) of superpixels, which is desirable but not always

197 possible (Achanta et al. 2012).

198 Semantic Texton Forests (STFs) is a supervised learning algorithm (Johnson and Shotton

199 2010) which uses kernel features instead of feature points during classifier training. STFs consist

200 of randomized decision forests, which are classifiers formed by several decision trees (Geurts et

201 al. 2006). Decision trees are trained using the bag of semantic textons that is created during

202 training. At that phase, features are extracted using a squared patch of pixels with predefined 
203 dimensions. Additionally, randomly selected subsets of features are utilized to assign a class

204 distribution and a binary function at each tree node. The class distribution represents the

205 probability of the tree node. The binary function is formed using the raw pixel values. The

206 advantage of this tactic is that it ensures greater speed and avoids over-fitting (Johnson and

207 Shotton 2010).

208 In general, there is no best learning technique (Kotsiantis et al. 2007; Wu et al. 2008).

209 The No Free Lunch Theorems of Optimization (Wolpert and Macready 1997) show that a unique

210 optimal method is impossible and the best technique always depends on the nature of the

211 problem. Accuracy is a characteristic that is highly desirable for the aim of this paper.

212 From image to world coordinates

213 One of the types of data that inspectors collect when inspecting the pavement network is

214 video of the lane and its surroundings. For those cases, it is useful to know the world coordinates

215 of the objects depicted. This is achievable by projecting the objects in the video frame from the

216 camera's optical plane to the pavement plane. This process is known as Inverse Perspective

217 Mapping (IPM) and it has seen application in pavement lane extraction (Aly 2008; Tapia-

218 Espinoza and Torres-Torriti 2013). IPM uses the pinhole camera model and the following

219 assumptions in order to be constructed:

220 a) The world coordinate system is fixed to the vehicle; $\left\{x^{w}, y^{w}, z^{w}\right\}$, and

221 b) The camera is positioned at the rear of the vehicle (in the middle) at a specific height $h$ from

222 the ground and is tilted towards the pavement plane forming an angle $\theta_{0}$ with an axis parallel to $223 x^{w}$ going through the focal point.

224 Figure 3 depicts the IPM model and equations (1) and (2) (Tapia-Espinoza and Torres-

225 Torriti 2013) show how to calculate the $\mathrm{x}$ and $\mathrm{y}$ coordinates of a point $\mathrm{P}$ in the world using its 
226 position within the image. The image plane is assumed to be of size $m \times n$ pixels. The point $\mathrm{p}$

227 can be represented with the coordinate pair $(u, v)$ when considering the reference system of the

228 camera, where $u$ and $v$ are the horizontal and vertical axes of the image sensor. It can also be

229 represented with the pair $(r, c)$ of the standard image row-column.

230 In conclusion, based on the state of research, although methods that automate the

231 detection of defects do exist, those are restricted to just one or a couple of defects at a time.

232 Hence, the necessity of applying laborious and time-consuming manual detection methods

233 remain. Another limitation of current methods is that some require expensive sensors for data

234 collection, which makes them unattractive for regular usage. On the other hand, methods that use

235 cheap sensors, such as accelerometers, are restricted to the lowest level of detail (presence)

236 which is not enough for practitioners. Given the limitations of the current practice and state of

237 research, we consider the following question: How can we efficiently detect most pavement

238 defects simultaneously? Our objective for this paper is to propose such an approach.

\section{PROPOSED SOLUTION}

240 There are three main parts of the research question that the authors are concentrating their focus.

241 One is the key word "efficiently", next is "most pavement defects", and last is "simultaneously".

242 In order to meet the objective of proposing an efficient solution, the authors aim to propose an

243 approach that is both low-cost and automated. Such a method could not only be appealing to

244 practitioners, but also easily and widely adopted. For that reason, the proposed method (figure 4

245 depicts a diagram of the overall vision of this research) utilizes parking cameras.

246 The idea of using such a sensor originates from the motivation of transforming everyday

247 road users into ubiquitous pavement condition reporters. Parking cameras already exist in many

248 cars, and they are gradually becoming a standardized feature, so there is no additional equipment 
249 cost required. It is also worth mentioning that all cars in the USA are mandated to have such a 250 sensor installed by 2018 (NHTSA 2014).

251 One camera is not enough for capturing all pavement defects, and those related to the z-

252 axis of the road (e.g. depressions and rutting) are particularly susceptible to this limitation. The 253 proposed solution utilizes an additional sensor to account for this limitation, allowing detection 254 of most defect types. Specifically, a vehicle dynamic sensor is used, which is capable of 255 capturing defects such as pavement elevations and depressions. Additionally, a GPS device 256 assists in the geo-tagging of all collected data in order to provide the location information of 257 detected defects. The suggested sensors are low-cost, providing a significantly cheaper 258 automated way of collecting data in comparison to current practice. Finally, after the detection of 259 defects, the solution includes the automatic assessment of their severity. Both defect detection 260 and assessment are proposed to be fully automated in contradiction to the mainly-manual current 261 practice. The proposed system does not require any lightning support since it is designed for use 262 under daytime fair weather conditions, which is consistent with the current practice.

263 This paper's scope is limited to the detection and classification of surface defects, 264 defining how parking camera feeds are used in support of the overall solution. The black-dotted 265 rectangle in Figure 4 provides a visual indication of how this paper's scope fits within the 266 framework of the larger solution. For that step of the overall vision, we hypothesize that applying 267 a supervised learning algorithm can detect several defects occurring in video frames in a more 268 efficient way than standalone algorithms. In particular, we propose the use of Semantic Texton

269 Forests (Johnson and Shotton 2010). The scope is restricted to the following pavement defects:

270 longitudinal and transverse cracks, patches and potholes. However, this method can address 271 additional defects (if trained accordingly) to cover them all when combined with vehicle 
272 dynamic sensor data. The method proposed in this paper automates the first and second steps of

273 the pavement condition assessment which can be seen in figure 1.

\section{RESEARCH METHODOLOGY}

\section{Pavement defects' multi-classifier}

The flowchart of figure 5 depicts the research activities followed for testing the

277 hypothesis of this paper. We initially collect pavement video data, and then process each frame

278 separately to prepare the ground truth. This step is performed manually and it is necessary for the

279 following step of the methodology. Ground truth video frame data include the following

280 metadata: 1) whether they are defective, 2) the type(s) of defects they include, and 3) the location

281 of each defect within the frame (coordinates of a polygon surrounding the defect). Once a

282 defective frame is prepared, we save two copies for training and testing purposes. One copy is

283 the plain image of the video frame and the other is a blank copy of the frame showing the

284 designated defective areas. The part of the frame that corresponds to areas other than defects is

285 marked as void. The first and second columns of figure 9 are examples of such copies. A specific

286 color represents each defect (see table 2).

287 The parameters that affect the performance of the method are set before the training step.

288 During training, the algorithm "learns" how to detect each defect. Video frames are randomly

289 selected from the previously prepared ground truth data. Only a portion of the ground truth data

290 is used in this step and the rest is used in the following one. At this stage, the plain image copy

291 facilitates the identification of the characteristic features of each defect, and the copy marked

292 with the designated defective areas directs the algorithm to search in the right part of the image.

293 STFs perform segmentation based on bag of semantic textons that groups decision trees and act

294 directly on the video frame pixels. Textons and priors are used as features for labeling pixels. 
After the training stage, we apply the trained STFs to the rest of the video frames (the

296 ones that have not been used in the previous stage) in order to test their performance. Both

297 training and testing are fully automated and don't need any human intervention. The outcome of

298 the process is segmented versions of the testing video frames produced by the algorithm. Last,

299 we calculate the statistics by comparing the results of the STFs with the ground truth to measure

300 the applicability of the algorithm and compare the combinations of parameters that affect its

301 performance.

302 Finding the Region of Interest

303 Parking cameras have wide angles of view, usually greater than 90 degrees, both horizontally

304 and vertically. For this reason, each video frame depicts more than just the travelled pavement

305 lane. Surroundings such as the sky, following vehicles, trees, etc. are also depicted (see example 306 in figure 6).

307 Since this study focuses on detecting specific types of pavement defects, the useful part 308 of the video frame is that which depicts the pavement lane only. We are naming this area myROI

309 (my Region of Interest), an example of which can be seen in figure 6. In order to calculate this

310 region, the following are used: 1) Equations of IPM, 2) Camera's position and specifications

311 (image analysis and lens' angles of view), 3) Pavement lane width, which is the other component

312 for calculating the side boundaries of myROI, and 4) Inspection guidelines, which uses the sizes

313 of defects that inspectors are looking for to define the upper bound of myROI.

314 First, the image coordinates are mapped to world coordinates using the equations of IPM.

315 The characteristics that are used at this step are the camera's position and specifications. Then

316 the real world distance that is represented by consecutive video frame rows is calculated. This

317 information is then used, along with the size of defects that need to be reported based on 
318 pavement defect manuals and the width of the road that is being inspected, in order to calculate

319 the vertices of myROI.

\section{IMPLEMENTATION \& RESULTS}

\section{Experimental setup}

We collected data using two cameras: an HP Elite Webcam, chosen to simulate a low-

323 resolution parking camera, and a Point Grey Blackfly 05S2M-CS that meets the standards of

324 parking cameras available in the market. Research on commercially available parking cameras

325 and car manufacturers' websites highlighted the specifications required to simulate existing

326 parking camera models. Parking cameras typically have low resolution (maximum 0.4MP) and

327 wide angles of view. Compared to the HP Elite, the Blackfly has higher resolution and a wider

328 horizontal angle of view. Table 3 includes both cameras' specifications. We mounted the

329 cameras on the test vehicle in a position consistent with car manufacturer specifications; that is

330 on the rear of the vehicle above or below the sign plate (see figure 7). Some vehicles have the

331 parking camera close to the trunk handle. However, we chose to position it below the sign plate.

332 The collected videos were saved locally to the laptop used in the field. The ground truth was

333 prepared afterwards in the office.

334 We used four metrics to measure the performance of the algorithm. Two metrics, overall

335 and average accuracies, correspond to the overall performance of STFs, and the other two,

336 average precision and area under curve, correspond to the performance of STFs in respect to

337 each defect. The total proportion of correctly detected pixels corresponds to the overall accuracy

338 (OA). Average accuracy (AA) refers to the average proportion of correctly detected pixels per

339 defect. Average precision (AP) is the fraction of correctly detected pixels (True Positive, TP)

340 over the sum of correctly and incorrectly detected pixels (False Positive, FP). The area formed 
341 when we plot TP versus FP represents the area under the curve (AuC). Good performance

342 corresponds to high AuC.

343 Many parameters affect the performance of STFs, so several parameter combinations

344 were tested. Specifically, the parameters changed at each test were the patch pixel size and the

345 maximum depth that a tree can reach during the training of the algorithm. Tables $4-7$

346 summarize the parameter combinations of each test, along with the produced results.

347 We performed the first round of tests (table 4) using the data collected with the HP

348 camera. The ground truth was marked using four categories (one for each defect). In the second

349 round of tests (table 5), which was performed using the same dataset, an additional category

350 called "healthy pavement" was added in the ground truth data. The third round of tests (table 6)

351 was performed using the data collected with the PG camera and the ground truth was prepared

352 using 5 categories ( 4 defects and healthy pavement). Finally, we performed the last round of tests

353 (table 7) using the data collected with the PG camera, and considering the calculated myROI.

354 myROI was calculated using MATLAB (see figure 8). The parameters were: 1) Camera

355 resolution - $800 \times 500$ pixels. As shown in figure 7, we did not position the camera in the middle

356 of the car, but slightly left from its center $(\sim 5 \mathrm{~cm}) .2)$ Lane width $-2.4 \mathrm{~m}$, and 3) Detection of

357 transverse cracks greater than $3.175 \mathrm{~mm}$. All copies of video frames (both plain image and image

358 with designated defective areas) produced during the ground truth preparation of the previous

359 round of tests were cropped using the above calculated myROI and used for this round of tests.

360 In summary, the control variables tested through our experiments were: 1) Image color:

361 color or monochrome, 2) Number of categories in ground truth data: 4 or 5, 3) STFs parameters:

362 Patch pixel size and maximum tree depth, and 4) Use of myROI. 
364 performed during daytime and the weather was sunny, cloudy or slightly rainy. The vehicle's

365 speed was $10-15 \mathrm{~km} / \mathrm{hr}$. Unexpected vibrations of the vehicle were minimal due to the low speed

366 and did not affect the quality of the data. We saved the video data locally and post-processed it

367 using a desktop computer (Intel Core i7 @ $3.4 \mathrm{GHz}, 8 \mathrm{~GB}$ Ram). The method was implemented

368 using C\# in the Visual Studio .NET framework. Right-click options and keyboard selection

369 functions were created in order to facilitate the step of preparing the ground truth and improve

370 the efficiency of the process. A pop-up menu was created for inserting the values of the

371 parameters that were tested.

\section{Results}

373 In the first round of experiments, the OA ranged between 0.69 and 0.79 , and AA ranged

374 from 0.55 to 0.73 . In the second round of experiments, where the additional category of healthy

375 pavement was used in the preparation of the ground truth data, the OA increased to between 0.86

376 and 0.89 . AA still remained quite low, ranging from 0.56 to 0.67 . The computational cost for

377 both rounds of experiments varied from 23 to 35 minutes. The algorithm performed better in the

378 third round of experiments, where we used the data collected from the PG camera. OA was

379 above 0.74 in all tests and the AA never fell below 0.7. In the final round of experiments, we

380 considered myROI and the results were further improved. OA ranged between 0.80 and 0.88 and

381 AA ranged between 0.71 and 0.8 . The third column of figure 9 shows some examples of the

382 derived results. The first row corresponds to an example from the first round of experiments, the

383 second row to the second round of experiments etc. The computational cost for the third and

384 fourth rounds of experiments varied from 120 to 150 minutes. The third and fourth round

385 experiments were performed 5 times each in order to ensure repeatability due to the fact that 
386 video frames are randomly selected both in training and in testing. The results shown in tables 6-

3877 constitute the average values and variance of the results produced from all the runs of the 388 experiments.

389 Tables 4-7 also show the performance of each defect individually on each test run. The 390 best results are highlighted in each table. Several successful combinations can accurately detect

391 longitudinal cracks. However, the best combinations are: 1) monochrome videos - 5 categories -

392 patch pixel size of 11 , and max tree depths $12 \& 14$, and 2) monochrome videos - 5 categories -

393 use of myROI - patch pixel size of 9 , and max tree depths $10 \& 15$. For transverse cracks the best

394 combination is: monochrome videos - 5 categories - patch pixel size of 13 , and max tree depths

395 of $10 \& 14$. For patches, the best combination is: monochrome videos - 5 categories - use of

396 myROI - patch pixel size of 11, and max tree depths of $10 \& 14$. Finally, the best combinations

397 for detecting potholes are: 1) colored videos - 5 categories - patch pixel size of 15 , and max tree

398 depths of $10 \& 14$, and 2) colored videos - 5 categories - patch pixel size of 13, and max tree

399 depths of $12 \& 16$. However, the following combination is worth mentioning due to its high

400 performance: monochrome videos - 5 categories - use of myROI - patch pixel size of 15 , and 401 max tree depths of $10 \& 14$.

402 Tables 8-11 show the confusion matrix for segmentation of each defect. The confusion 403 matrices correspond to the best performing combination of parameters based on the OA and AA.

404 For the first round of experiments the average accuracy for region segmentation is $59 \%$. In the 405 second round of experiment, the average accuracy increases to $60 \%$. In the third round of 406 experiment the average region segmentation accuracy is $72 \%$, and in the final round of 407 experiments it is $74 \%$.

\section{CONCLUSIONS \& FUTURE WORK}


410 subjectivity and time consumption. Multiple research efforts have focused on automating this

411 task. However, all proposed methods focus on only one or a couple of defects. Even if

412 automated methods exist for detecting some defects, the remaining defect types need to be

413 detected manually, and the limitations and issues of the current practice remain.

414 In this paper, we tested the application of Semantic Texton Forests, a supervised learning

415 algorithm, to detect several pavement defects in video frames. STFs was selected due to the

416 multiple features it uses for segmentation, which are texture, layout and context. Superpixel

417 algorithms were rejected because of the existing concerns regarding controlling the amount of

418 superpixels and their compactness. Each pavement defect has its own size, which varies

419 significantly, so it would have been very challenging or even impossible to decide on a

420 "universal" superpixel shape and/or size to ensure compactness.

421 The main challenge was the preparation of the ground truth which was manual.

422 However, the several options built in the platform for this step made it easy and quick. The idea

423 is to test the usage of parking cameras for potentially crowdsourcing the task of pavement

424 monitoring to everyday pavement users. We used a camera that follows vehicle manufacturer

425 standards for parking cameras in the experiments. Several combinations of parameters, such as

426 the patch pixel size and the max tree depth, were tested. Those parameters affect the

427 performance of the algorithm. The built-in pop up menu for inserting the parameters affected the

428 applicability of the method positively, since it provides a friendly user interface. Additionally,

429 we applied the theory of Inverse Perspective Mapping for isolating the pavement lane in the

430 video frame and restricting the application of the algorithm in that area only, while considering

431 the size of each defect that inspectors are looking for. 
The initial results of the experiments with the HP camera were quite low. This is

433 probably due to the low resolution of the camera and the restricted information that such a

434 camera can capture. Additionally, in that round of experiments the detection of the transverse

435 crack was very low. This is explained by the smaller sample that was available in the data in

436 comparison to the other defects. This shows that more samples are necessary for the algorithm to

437 "learn" the object.

438 The additional information of healthy pavement in the ground truth data resulted in an

439 improvement of the performance. This shows that the use of more categories is beneficial to the

440 improvement of the algorithm's performance. The performance of the algorithm was even better

441 on the data collected with the PG camera, which follows parking camera standards. This is due to

442 the higher camera resolution. Those data also allowed the creation of a larger database. The

443 database with the HP camera consists of 230 video frames, whereas the second one includes 546

444 video frames. Finally, we derived even better results when we considered myROI. This is

445 because the algorithm was restricted to the area were defects are expected to be found. In regards

446 to each defect detection individually, different combinations of the control variables are

447 achieving the best performing results.

448 The method was slower in the experiments using the PG camera data. The difference can

449 be explained due to the following reasons: 1) the database created with the PG camera was

450 almost double the size of that created with the HP camera, and 2) the image resolution of the

451 second database is higher than the first, which means that the total number of pixels is much

452 bigger. The performance gain can be viewed in the results that the method produced. In the

453 initial experiments the overall accuracy varies from $69 \%$ to $79 \%$, whereas in the final

454 experiments it improved up to $85 \%$. The same holds for the segmentation of each region in the 
455 video frame, which has an accuracy of 59\% in the first round of experiments and increases to

$45674 \%$ in the last one. The initial dataset proved the practicability of low-resolution cameras for the

457 automation pavement defects. The second dataset and the produced results show the applicability 458 of the method.

459 The results show that the method performs well under fair weather. STFs uses texture as 460 one of the features for segmentation and this assists in the differentiation amongst the different 461 defects. For example potholes are coarser than patches and the can be detected even in direct

462 sunlight. Intensity values are also incorporated in the segmentation. Even if asphalt is already 463 dark, the defects' intensities are usually darker and the difference assists the detection as well. 464 Also, the results show that the method performs well when data is collected in low speeds. 465 Hence, the concept of using parking cameras for detecting pavement defects is proved. In order 466 though for this framework to be applied commercially, it should be tested in higher speeds and 467 that consists part of our future work.

468 To conclude, STFs perform well for the detection of surface pavement defects. However, 469 other defects such as rutting, depressions and elevations also need to be incorporated for a fully 470 automated pavement condition monitoring method. These defects are related to the z-axis of the 471 road profile and could be detected in vehicle dynamic sensor data as suggested in the proposed 472 solution. The type and number of the sensors needed to capture this type of information needs to 473 be investigated. The same holds for the positioning of those sensors on or within the vehicle. The 474 measurement of the detected defects is also necessary for their evaluation. Although the scope of 475 this paper is restricted to the level of detection, it could be extended to the next level of detail. 476 However, it would be necessary to eliminate the distortion that wide angles are causing. The 477 method is still practical, since it can direct inspectors to the spots where defects should be further 
investigated and save the time of searching for them. Another interesting research problem is the

479 transfer of the collected data from the 'inspection' vehicle(s) to the pavement maintenance

480 authority. Hence, our future work will be directed towards these additional problems.

\section{Acknowledgements}

482 This material is based in part upon work supported by the National Science Foundation under

483 Grant Number 1031329. Any opinions, findings, and conclusions or recommendations expressed

484 in this material are those of the authors and do not necessarily reflect the views of the National

485 Science Foundation.

486

487

488

489

490

491

492

493

494

495

496

497

498

499

500

501

502

503

504

505

506

507

508

509

510

511

512

513

514

\section{References}

Achanta, R., Shaji, A., Smith, K., Lucchi, A., Fua, P., and Süsstrunk, S. (2012). "SLIC Superpixels Compared to State-of-the-Art Superpixel Methods." IEEE Transactions on Pattern Analysis and Machine Intelligence, 34(11), 2274-2282.

Adu-Gyamfi, Y. O., Okine, N. A., Garateguy, G., Carrillo, R., and Arce, G. R. (2011). "Multiresolution information mining for pavement crack image analysis." Journal of Computing in Civil Engineering, 26(6), 741-749.

Aly, M. (2008). "Real time detection of lane markers in urban streets." Intelligent Vehicles Symposium, 2008 IEEE, IEEE, 7-12.

Amarasiri, S., Gunaratne, M., and Sarkar, S. (2009). "Modeling of Crack Depths in Digital Images of Concrete Pavements Using Optical Reflection Properties." Journal of Transportation Engineering, 136(6), 489-499.

ASCE. (2013). "2013 report card for America's infrastructure." $<\mathrm{http}: / /$ www.infrastructurereportcard.org/> (Jul. 20, 2013).

Attoh-Okine, N., and Adarkwa, O. (2013). Pavement Condition Surveys - Overview of Current Practices. Project Report, Delaware Center for Transportation, Newark, DE.

Audit Commission. (2011). Going the distance - Achieving better value for money in road maintenance. Local government report, London, UK.

Austroads. (2011). Pavement Rutting Measurement with a Multi-Laser Profilometer. Austroads Test Method AG.

Balali, V., and Golparvar-Fard, M. (2015). "Segmentation and recognition of roadway assets from car-mounted camera video streams using a scalable non-parametric image parsing method." Automation in Construction, 49, Part A, 27-39.

Battiato, S., Cafiso, S., Di Graziano, A., Rizzo, L., and Stanco, F. (2006). "Pavement Surface Distress by Using Non-linear Image Analysis Techniques."

Battiato, S., Stanco, F., Cafiso, S., and Di Graziano, A. (2007). "Adaptive Imaging Techniques for Pavement Surface Distress Analysis." Communications to SIMAI Congress.

Bay, H., Ess, A., Tuytelaars, T., and Van Gool, L. (2008). "Speeded-Up Robust Features (SURF)." Computer Vision and Image Understanding, 110(3), 346-359. 
Bianchini, A., Bandini, P., and Smith, D. W. (2010). "Interrater reliability of manual pavement distress evaluations." Journal of Transportation Engineering, 136(2), 165-172.

Cafiso, S., Di Graziano, A., and Battiato, S. (2006). "Evaluation of pavement surface distress using digital image collection and analysis." Seventh International Congress on Advances in Civil Engineering.

CBI, and URS. (2014). Taking the long view: a new approach to infrastructure,. Infrastructure survey, UK.

Chang, K. T., Chang, J. R., and Liu, J. K. (2005). "Detection of pavement distresses using 3D laser scanning technology." Proc. of the 2005 ASCE Int. Conf. on Computing in Civil Engineering, 105.

Cheng, H. D., Shi, X. J., and Glazier, C. (2003). "Real-time image thresholding based on sample space reduction and interpolation approach." Journal of computing in civil engineering, 17(4), 264-272.

Cord, A., and Chambon, S. (2012). "Automatic Road Defect Detection by Textural Pattern Recognition Based on AdaBoost." Computer-Aided Civil and Infrastructure Engineering, 27(4), 244-259.

DfT, D. for T. U. (2011). "SCANNER User Guide and Specification." <http://www.pcis.org.uk/index.php?p=6/8/0/list,0,58> (Jul. 3, 2013).

DfT, D. for T. U. (2015). Statistical Release - Road Lengths in Great Britain 2014.

Doumiati, M., Victorino, A., Charara, A., and Lechner, D. (2011). "Estimation of road profile for vehicle dynamics motion: experimental validation." American Control Conference (ACC), 2011, 5237-5242.

Dye Management Group, Inc. (2015). "Level of Service Condition Assessments - Data Collection Manual." Alabama Department of Transportation.

Felzenszwalb, P. F., and Huttenlocher, D. P. (2004). "Efficient Graph-Based Image Segmentation." International Journal of Computer Vision, 59(2), 167-181.

FHWA. (2003). Distress Identification Manual for the Long-Term Pavement Performance Program. Federal Highway Administration.

Gavilán, M., Balcones, D., Marcos, O., Llorca, D. F., Sotelo, M. A., Parra, I., Ocaña, M., Aliseda, P., Yarza, P., and Amírola, A. (2011). "Adaptive road crack detection system by pavement classification." Sensors, 11(10), 9628-9657.

Georgieva, K., Koch, C., and König, M. (2015). "Wavelet Transform on Multi-GPU for RealTime Pavement Distress Detection." Computing in Civil Engineering 2015, ASCE, 99106.

Geurts, P., Ernst, D., and Wehenkel, L. (2006). "Extremely randomized trees.” Machine learning, 63(1), 3-42.

Ghanta, S., Birken, R., and Dy, J. (2012). "Automatic road surface defect detection from grayscale images." SPIE Smart Structures and Materials+ Nondestructive Evaluation and Health Monitoring, 83471E-83471E.

González, A., O'brien, E. J., Li, Y.-Y., and Cashell, K. (2008). "The use of vehicle acceleration measurements to estimate road roughness." Vehicle System Dynamics, 46(6), 483-499.

Haas, C. (1996). "Evolution of an automated crack sealer: a study in construction technology development." Automation in construction, 4(4), 293-305.

Harris, N. K., Gonzalez, A., OBrien, E. J., and McGetrick, P. (2010). "Characterisation of pavement profile heights using accelerometer readings and a combinatorial optimisation technique." Journal of Sound and Vibration, 329(5), 497-508.

560 
561

562

563

564

565

566

567

568

569

570

571

572

573

574

575

576

577

578

579

580

581

582

583

584

585

586

587

588

589

590

591

592

593

594

595

596

597

598

599

600

601

602

603

604

605

Huang, Y., and Xu, B. (2006). "Automatic inspection of pavement cracking distress.” Journal of Electronic Imaging, 15(1), 013017-013017.

ICE. (2014). The state of the nation - Infrastructure 2014. Institution of Civil Engineers.

Imine, H., and Delanne, Y. (2005). "Triangular observers for road profiles inputs estimation and vehicle dynamics analysis." Robotics and Automation, 2005. ICRA 2005. Proceedings of the 2005 IEEE International Conference on, 4751-4756.

Imine, H., Delanne, Y., and M'sirdi, N. K. (2006). "Road profile input estimation in vehicle dynamics simulation." Vehicle System Dynamics, 44(4), 285-303.

Imine, H., M Sirdi, N. K., and Delanne, Y. (2003). "Adaptive observers and estimation of the road profile." SAE SP, 175-180.

Islam, S., Buttlar, W., Aldunate, R., and Vavrik, W. (2014). "Measurement of Pavement Roughness Using Android-Based Smartphone Application." Transportation Research Record: Journal of the Transportation Research Board, 2457, 30-38.

Jahanshahi, Mohammad R., Jazizadeh, Farrokh, Masri, Sami F., and Becerik-Gerber Burcin. (2013). "Unsupervised Approach for Autonomous Pavement-Defect Detection and Quantification Using an Inexpensive Depth Sensor." Journal of Computing in Civil Engineering, 27(6), 743-754.

Jiang, C., and Tsai, Y. J. (2015). "Enhanced Crack Segmentation Algorithm Using 3D Pavement Data." Journal of Computing in Civil Engineering, 04015050.

Jing, L., and Aiqin, Z. (2010). "Pavement crack distress detection based on image analysis." Machine Vision and Human-Machine Interface (MVHI), 2010 International Conference on, 576-579.

Jog, G. M., Koch, C., Golparvar-Fard, M., and Brilakis, I. (2012). "Pothole Properties Measurement through Visual 2D Recognition and 3D Reconstruction." Computing in Civil Engineering (2012), 553-560.

Johnson, M., and Shotton, J. (2010). "Semantic texton forests." Computer Vision, Springer, 173203.

Johnsson, R., and Odelius, J. (2012). "Methods for road texture estimation using vehicle measurements."

Kamaliardakani, M., Sun, L., and Ardakani, M. K. (2014). "Sealed-crack detection algorithm using heuristic thresholding approach." Journal of Computing in Civil Engineering, 30(1), 04014110.

Kaul, V., Tsai, Y., and Mersereau, R. (2010). "Quantitative Performance Evaluation Algorithms for Pavement Distress Segmentation." Transportation Research Record: Journal of the Transportation Research Board, 2153, 106-113.

Kim, Y. S., Yoo, H. S., Lee, J. H., and Han, S. W. (2009). "Chronological development history of $\mathrm{X}-\mathrm{Y}$ table based pavement crack sealers and research findings for practical use in the field." Automation in Construction, 18(5), 513-524.

Koch, C., and Brilakis, I. (2011). "Pothole detection in asphalt pavement images." Advanced Engineering Informatics, 25(3), 507-515.

Koch, C., Jog, G. M., and Brilakis, I. (2012). "Automated Pothole Distress Assessment Using Asphalt Pavement Video Data." Journal of Computing in Civil Engineering, 27(4), 370378.

Kotsiantis, S. B., Zaharakis, I. D., and Pintelas, P. E. (2007). "Supervised machine learning: A review of classification techniques." 
606

607

608

609

610

611

612

613

614

615

616

617

618

619

620

621

622

623

624

625

626

627

628

629

630

631

632

633

634

635

636

637

638

639

640

641

642

643

644

645

646

647

648

649

650

Lakusić, S., Brcić, D., and Tkalcević Lakusić, V. (2011). “Analysis of Vehicle Vibrations-New Approach to Rating Pavement Condition of Urban Roads." PROMET-

Traffic \&Transportation, 23(6), 485-494.

Laurent, J., Hebert, J. F., Lefebvre, D., and Savard, Y. (2012). "Using 3D Laser Profiling Sensors for the Automated Measurement of Road Surface Conditions." Mechanisms, Modeling, Testing, Detection and Prevention Case Histories, Springer, 157-159.

Levinshtein, A., Stere, A., Kutulakos, K. N., Fleet, D. J., Dickinson, S. J., and Siddiqi, K. (2009). "Turbopixels: Fast superpixels using geometric flows." Pattern Analysis and Machine Intelligence, IEEE Transactions on, 31(12), 2290-2297.

Lin, J., and Liu, Y. (2010). "Potholes detection based on SVM in the pavement distress image." Distributed Computing and Applications to Business Engineering and Science (DCABES), 2010 Ninth International Symposium on, 544-547.

Liosatos, J. (2013). Road Maintenance in the PAG Region: Challenges and Opportunities. Tuscon, Arizona.

Li, Q., and Liu, X. (2008). "Novel approach to pavement image segmentation based on neighboring difference histogram method." Image and Signal Processing, 2008. CISP'08. Congress on, 792-796.

Li, Q., Yao, M., Yao, X., and Xu, B. (2010). “A real-time 3D scanning system for pavement distortion inspection." Measurement Science and Technology, 21(1), 015702.

Liu, F., Xu, G., Yang, Y., Niu, X., and Pan, Y. (2008). "Novel approach to pavement cracking automatic detection based on segment extending." Knowledge Acquisition and Modeling, 2008. KAM'08. International Symposium on, 610-614.

Lokeshwor, H., Das, L. K., and Goel, S. (2013). "Robust method for automated segmentation of frames with/without distress from road surface video clips." Journal of Transportation Engineering, 140(1), 31-41.

Lowe, D. G. (2004). "Distinctive image features from scale-invariant keypoints." International journal of computer vision, 60(2), 91-110.

Ma, C., Wang, W., Zhao, C., Di, F., and Zhu, Z. (2009). "Pavement cracks detection based on FDWT." Computational Intelligence and Software Engineering, 2009. CiSE 2009. International Conference on, $1-4$.

Maode, Y., Shaobo, B., Kun, X., and Yuyao, H. (2007). "Pavement crack detection and analysis for high-grade highway." Electronic Measurement and Instruments, 2007. ICEMI'07. 8th International Conference on, 4-548.

Mathavan, S., Rahman, M., Stonecliffe-Jones, M., and Kamal, K. (2014). "Pavement Raveling Detection and Measurement from Synchronized Intensity and Range Images." Transportation Research Record: Journal of the Transportation Research Board, 2457, $3-11$.

McTavish, T. H. (2012). Performance Audit of the Measurement of State Highway Pavement Conditions. Audit Report, Michigan Department of Transportation, Lansing, Michigan.

MnDOT. (2003). “Mn/DOT Distress Identification Manual.” Minnesota Department of Transportation.

MnDOT. (2009). Pavement Condition Executive Summary. MnDOT/OMRR-PM--2009-01, Minnesota Department of Transportation.

NAMS Group. (2006). International infrastructure management manual. National Asset Management Steering Group. 
651

652

653

654

655

656

657

658

659

660

661

662

663

664

665

666

667

668

669

670

671

672

673

674

675

676

677

678

679

680

681

682

683

684

685

686

687

688

689

690

691

692

693

694

695

696

National Audit Office. (2014). Maintaining stategic infrastructure: roads. Summary, National Audit Office, UK.

Nejad, F. M., and Zakeri, H. (2011). "An optimum feature extraction method based on WaveletRadon Transform and Dynamic Neural Network for pavement distress classification." Expert Systems with Applications, 38(8), 9442-9460.

Nguyen, T. S., Avila, M., and Begot, S. (2009). "Automatic detection and classification of defect on road pavement using anisotropy measure." Proceeding of EUSIPCO, 617-621.

Ngwangwa, H. M., Heyns, P. S., Labuschagne, F. J. J., and Kululanga, G. K. (2010). "Reconstruction of road defects and road roughness classification using vehicle responses with artificial neural networks simulation." Journal of Terramechanics, 47(2), 97-111.

NHTSA, 2014. (2014). "Federal Motor Vehicle Safety Standards; Rear Visibility." FEDERAL REGISTER-The Daily Journal of the United States Government, $<$ https://www.federalregister.gov/articles/2014/04/07/2014-07469/federal-motor-vehiclesafety-standards-rear-visibility> (May 6, 2014).

Nishiyama, S., Minakata, N., Kikuchi, T., and Yano, T. (2015). "Improved digital photogrammetry technique for crack monitoring." Advanced Engineering Informatics, Collective Intelligence Modeling, Analysis, and Synthesis for Innovative Engineering Decision MakingSpecial Issue of the 1st International Conference on Civil and Building Engineering Informatics, 29(4), 851-858.

Nitsche, P., Stütz, R., Kammer, M., and Maurer, P. (2012). "Comparison of Machine Learning Methods for Evaluating Pavement Roughness Based on Vehicle Response." Journal of Computing in Civil Engineering, 28(4), 04014015.

Peng, B., Jiang, Y., and Pu, Y. (2015). "Review on Automatic Pavement Crack Image Recognition Algorithms." Journal of Highway and Transportation Research and Development (English Edition), 9(2), 13-20.

PublicWorksTraining. (2014). PASER Data Collection Best Practices Manual - Indiana LTAP PASER Training 2014. Houghton, MI.

Radopoulou, S. C., and Brilakis, I. (2015). "Patch detection for pavement assessment." Automation in Construction, 53, 95-104.

Rami, K. Z., and Kim, Y.-R. (2015). Nebraska Data Collection. Lincoln, NE.

Richardson, D. N., Lusher, S. M., and Luna, R. (2015). MoDOT Pavement Preservation Research Program. Volume II, Data Collection for Pavement Management: Historical Data Mining and Production of Data. Missouri University of Science and Technology for Missouri Department of Transportation.

Rick Miller. (2015). Condition Survey Report. Kansas Department of Transport.

Salari, E., and Bao, G. (2011). "Pavement distress detection and severity analysis." IS\&T/SPIE Electronic Imaging, 78770C-78770C.

Shotton, J., Winn, J., Rother, C., and Criminisi, A. (2009). “Textonboost for image understanding: Multi-class object recognition and segmentation by jointly modeling texture, layout, and context." International Journal of Computer Vision, 81(1), 2-23.

Solhmirzaei, A., Azadi, S., and Kazemi, R. (2012). "Road profile estimation using wavelet neural network and 7-DOF vehicle dynamic systems." Journal of mechanical science and technology, 26(10), 3029-3036.

Sorncharean, S., and Phiphobmongkol, S. (2008). "Crack detection on asphalt surface image using enhanced grid cell analysis." Electronic Design, Test and Applications, 2008. DELTA 2008. 4th IEEE International Symposium on, 49-54. 
Subirats, P., Dumoulin, J., Legeay, V., and Barba, D. (2006). "Automation of pavement surface crack detection using the continuous wavelet transform." Image Processing, 2006 IEEE International Conference on, 3037-3040.

Sun, Y., Salari, E., and Chou, E. (2009). "Automated pavement distress detection using advanced image processing techniques.” Electro/Information Technology, 2009. eit'09. IEEE International Conference on, 373-377.

Sy, N. T., Avila, M., Begot, S., and Bardet, J.-C. (2008). "Detection of defects in road surface by a vision system." Electrotechnical Conference, 2008. MELECON 2008. The 14th IEEE Mediterranean, 847-851.

Tapia-Espinoza, R., and Torres-Torriti, M. (2013). "Robust Lane Sensing and Departure Warning under Shadows and Occlusions." Sensors, 13(3), 3270-3298.

Teomete, E., Amin, V. R., Ceylan, H., and Smadi, O. (2005). "Digital image processing for pavement distress analyses." Proceedings of the 2005 Mid-Continent Transportation Research Symposium, 1-13.

Tsai, Y.-C. J., and Li, F. (2012). "Critical assessment of detecting asphalt pavement cracks under different lighting and low intensity contrast conditions using emerging 3D laser technology." Journal of Transportation Engineering, 138(5), 649-656.

Tsai, Y.-C., Kaul, V., and Mersereau, R. M. (2009). "Critical assessment of pavement distress segmentation methods." Journal of Transportation Engineering, 136(1), 11-19.

Tsai, Y. J., Li, F., and Wu, Yiching. (2013). "A New Rutting Measurement Method Using Emerging 3D Line-Lase-Imaging System.” 6(5), 667-672.

Uijlings, J. R., Smeulders, A. W., and Scha, R. J. (2010). "Real-time visual concept classification." Multimedia, IEEE Transactions on, 12(7), 665-681.

UKPMS. (2005). "The UKPMS user manual.” United Kingdom Pavement Management System.

Uslu, B., Golparvar-Fard, M., and de la Garza, J. M. (2011). "Image-based 3D reconstruction and recognition for enhanced highway condition assessment." Proceedings of the 2011 ASCE Intl. Workshop on Computing in Civil Engineering, Miami, FL, 67-76.

Veksler, O., Boykov, Y., and Mehrani, P. (2010). "Superpixels and supervoxels in an energy optimization framework." Computer Vision-ECCV 2010, Springer, 211-224.

Vilacca, J. L., Fonseca, J. C., Pinho, A. C. M., and Freitas, E. (2010). "3D surface profile equipment for the characterization of the pavement texture-TexScan." Mechatronics, 20(6), 674-685.

Wang, K. C., and Gong, W. (2005). "Real-time automated survey system of pavement cracking in parallel environment." Journal of infrastructure systems, 11(3), 154-164.

Wang, K. C., Hou, Z., and Williams, S. (2010). "Precision test of cracking surveys with the automated distress analyzer." Journal of Transportation Engineering, 137(8), 571-579.

Wang, Q., McDaniel, J. G., Sun, N. X., and Wang, M. L. (2013). "Road profile estimation of city roads using DTPS." SPIE Smart Structures and Materials+ Nondestructive Evaluation and Health Monitoring, 86923C-86923C.

Wei, L., Fwa, T. F., and Zhe, Z. (2005). "Wavelet analysis and interpretation of road roughness." Journal of transportation engineering, 131(2), 120-130.

Werro, P. (2013). "SCANNER surveys."

Wolpert, D. H., and Macready, W. G. (1997). "No free lunch theorems for optimization." Evolutionary Computation, IEEE Transactions on, 1(1), 67-82. 
Wu, L., Mokhtari, S., Nazef, A., Nam, B., and Yun, H.-B. (2016). "Improvement of CrackDetection Accuracy Using a Novel Crack Defragmentation Technique in Image-Based Road Assessment." Journal of Computing in Civil Engineering, 30(1), 04014118.

Wu, X., Kumar, V., Quinlan, J. R., Ghosh, J., Yang, Q., Motoda, H., McLachlan, G. J., Ng, A., Liu, B., and Philip, S. Y. (2008). "Top 10 algorithms in data mining." Knowledge and Information Systems, 14(1), 1-37.

Xu, G., Ma, J., Liu, F., and Niu, X. (2008). "Automatic recognition of pavement surface crack based on Bp neural network." Computer and Electrical Engineering, 2008. ICCEE 2008. International Conference on, 19-22.

Yao, X., Yao, M., and Xu, B. (2008). "Automated Detection and Identification of Area-based Distress in Concrete Pavements." Seventh International Conference on Managing Pavement Assets.

Ying, L., and Salari, E. (2010). "Beamlet Transform-Based Technique for Pavement Crack Detection and Classification." Computer-Aided Civil and Infrastructure Engineering, 25(8), 572-580.

Yousefzadeh, M., Azadi, S., and Soltani, A. (2010). "Road profile estimation using neural network algorithm." Journal of mechanical science and technology, 24(3), 743-754.

Yu, B. X., and Yu, X. (2006). "Vibration-based system for pavement condition evaluation." Applications of Advanced Technology in Transportation. The Ninth International Conference.

Yun, H.-B., Mokhtari, S., and Wu, L. (2015). "Crack Recognition and Segmentation Using Morphological Image-Processing Techniques for Flexible Pavements." Transportation Research Record: Journal of the Transportation Research Board, (2523), 115-124.

Yu, S.-J., Sukumar, S. R., Koschan, A. F., Page, D. L., and Abidi, M. A. (2007). "3D reconstruction of road surfaces using an integrated multi-sensory approach." Optics and lasers in engineering, 45(7), 808-818.

Zhang, G. P. (2000). "Neural networks for classification: a survey." Systems, Man, and Cybernetics, Part C: Applications and Reviews, IEEE Transactions on, 30(4), 451-462.

Zhou, H., Jalayer, M., Gong, J., Hu, S., and Grinter, M. (2013). Investigation of Methods and Approaches for Collecting and Recording Highway Inventory Data.

Zhou, J., Huang, P. S., and Chiang, F.-P. (2003). "Wavelet-aided pavement distress image processing." Optical Science and Technology, SPIE's 48th Annual Meeting, 728-739.

773 
Table 1 Reference list on methods for automating pavement defect detection \& measurement

\section{Presence}

1. Cheng et al. 2003

2. Li and Liu 2008

3. Battiato et al. 2006, 2007

4. Zhou et al. 2003

5. Doumiati et al. 2011

6. González et al. 2008

7. Harris et al. 2010

8. Imine and Delanne 2005

9. Imine et al. 2003, 2006

10. Johnsson\&Odelius 2012

11. Ngwangwa et al. 2010

12. Solhmirzaei et al. 2012

13. Wang et al. 2013

14. Wei et al. 2005

15. Yousefzadeh et al. 2010

16. $\mathrm{Yu}$ and $\mathrm{Yu} 2006$

17. Lakusić et al. 2011

18. Georgieva et al. 2015

19. Lokeshwor et al. 2013

\section{Detection}

20. Jiang and Tsai 2015

21. Kaul et al. 2010

22. Yun et al. 2015

23. Adu-Gyamfi et al. 2011

24. Cord \& Chambon 2012

25. Gavilán et al. 2011

26. Ghanta et al. 2012

27. Huang and $\mathrm{Xu} 2006$

28. Jing and Aiqin 2010

29. Kamaliardakani et al. 2014

30. Liu et al. 2008

31. Ma et al. 2009

32. Nejad and Zakeri 2011

33. Peng et al. 2015 (r)

34. Sorncharean and Phiphobmongkol 2008

35. Subirats et al. 2006

36. Sy et al. 2008

37. Tsai et al. 2009 (r)

38. Tsai and Li 2012

39. Wu et al. 2016

40. Xu et al. 2008

41. Rado and Brilakis 2015

42. Chang et al. 2005

43. Jog et al. 2012

44. Koch and Brilakis 2011

45. Koch et al. 2012

46. Mathavan et al. 2014

47. Jahanshahi et al. 2013

48. Cafiso et al. 2006

49. Lin and Liu 2010

50. Yao et al. 2008

51. Uslu et al. 2011

\section{Measurement}

52. Wang et al. 2010

53. Amarasiri et al. 2009

54. Haas 1996

55. Kim et al. 2009

56. Laurent et al. 2012

57. Maode et al. 2007

58. Nejad and Zakeri 2011

59. Nguyen et al. 2009

60. Nishiyama et al. 2015

61. Salari and Bao 2011

62. Sun et al. 2009

63. Teomete et al. 2005

64. Wang and Gong 2005

65. Ying and Salari 2010

66. Liu et al. 2008

67. Li et al. 2010

68. Austroads 2011

69. Islam et al. 2014

70. Nitsche et al. 2012

71. Tsai et al. 2013

72. Vilacca et al. 2010 
Table 2 Pavement defect and its representative color in the ground truth data

780

781

782

783 Table 4 Tested parameters and results of STFs (data captured by HP camera using 4 categories)

\begin{tabular}{|c|c|c|c|c|c|c|c|c|c|}
\hline & $\begin{array}{c}\text { Test } \\
1\end{array}$ & $\begin{array}{c}\text { Test } \\
2\end{array}$ & $\begin{array}{c}\text { Test } \\
3\end{array}$ & $\begin{array}{c}\text { Test } \\
4\end{array}$ & $\begin{array}{c}\text { Test } \\
5\end{array}$ & $\begin{array}{c}\text { Test } \\
6\end{array}$ & $\begin{array}{c}\text { Test } \\
7\end{array}$ & $\begin{array}{c}\text { Test } \\
8\end{array}$ \\
\hline & Box size & 15 & 11 & 13 & 9 & 17 & 15 & 15 & 15 \\
\hline & \multirow{2}{*}{$\begin{array}{c}\text { Max tree } \\
\text { depth } \\
\end{array}$} & $10 \&$ & $10 \&$ & $10 \&$ & $10 \&$ & $10 \&$ & $11 \&$ & $12 \&$ & $15 \&$ \\
\hline & & 14 & 14 & 14 & 14 & 14 & 13 & 16 & 16 \\
\hline \multirow{4}{*}{$\begin{array}{c}\text { Longitudinal } \\
\text { crack }\end{array}$} & Ov.Acc. & 0.78 & 0.69 & 0.73 & 0.78 & 0.76 & 0.78 & 0.78 & 0.79 \\
\hline & $A v \cdot A c c$ & 0.64 & 0.55 & 0.73 & 0.62 & 0.60 & 0.60 & 0.64 & 0.65 \\
\hline & $A v \cdot P r$. & 0.95 & 0.95 & 0.95 & 0.97 & 0.96 & 0.96 & 0.90 & 0.96 \\
\hline & $A u C$ & 0.86 & 0.80 & 0.80 & 0.90 & 0.90 & 0.90 & 0.90 & 0.89 \\
\hline \multirow{2}{*}{$\begin{array}{c}\text { Transverse } \\
\text { crack }\end{array}$} & Av.Pr. & 0.20 & 0.04 & 0.01 & 0.28 & 0.02 & 0.27 & 0.35 & 0.01 \\
\hline & $A u C$ & 0.85 & 0.76 & 0.26 & 0.73 & 0.68 & 0.93 & 0.75 & 0.29 \\
\hline \multirow{2}{*}{ Patch } & $A v \cdot P r$. & 0.75 & 0.86 & 0.68 & 0.81 & 0.80 & 0.69 & 0.62 & 0.84 \\
\hline & $A u C$ & 0.88 & 0.91 & 0.81 & 0.92 & 0.88 & 0.86 & 0.80 & 0.92 \\
\hline \multirow{2}{*}{ Pothole } & Av.Pr. & 0.89 & 0.99 & 0.84 & 0.90 & 0.90 & 0.82 & 0.81 & 0.92 \\
\hline & $A u C$ & 0.96 & 0.99 & 0.95 & 0.96 & 0.96 & 0.90 & 0.96 & 0.96 \\
\hline
\end{tabular}

784

\begin{tabular}{c|cc}
\hline & HP Elite Autofocus & Point Grey Blackfly \\
& Webcam & O5S2M-CS \\
\hline Image resolution & $640 \times 480$ & $800 \times 500$ \\
Horizontal angle of view & $\sim 50^{\circ}$ & $133^{\circ}$ \\
Frame rate per second & 30 & 50 \\
Color & RGB & Monochrome \\
\hline
\end{tabular}

Table 3 Specifications of cameras used for collecting data

\begin{tabular}{l|l}
\hline Type of defect & Color \\
\hline Longitudinal crack & Red \\
Transverse crack & Blue \\
Patch & Yellow \\
Pothole & Pink \\
Healthy pavement & Grey \\
Void & Black \\
\hline
\end{tabular}

785

786

787

788

789

790

791 
792 Table 5 Tested parameters and results of STFs (data captured by HP camera using 5 categories)

\begin{tabular}{|c|c|c|c|c|c|c|c|c|c|}
\hline & $\begin{array}{c}\text { Test } \\
1\end{array}$ & $\begin{array}{c}\text { Test } \\
2\end{array}$ & $\begin{array}{c}\text { Test } \\
3\end{array}$ & $\begin{array}{c}\text { Test } \\
4\end{array}$ & $\begin{array}{c}\text { Test } \\
5\end{array}$ & $\begin{array}{c}\text { Test } \\
6\end{array}$ & $\begin{array}{c}\text { Test } \\
7\end{array}$ & $\begin{array}{c}\text { Test } \\
8\end{array}$ \\
\hline & Box size & 15 & 11 & 13 & 9 & 17 & 13 & 13 & 13 \\
\hline & Max tree & $10 \&$ & $10 \&$ & $10 \&$ & $10 \&$ & $10 \&$ & $11 \&$ & $12 \&$ & $15 \&$ \\
\hline & depth & 14 & 14 & 14 & 14 & 14 & 13 & 16 & 16 \\
\hline & Ov.Acc. & 0.84 & 0.87 & 0.89 & 0.87 & 0.86 & 0.89 & 0.86 & 0.89 \\
\hline & $A v \cdot A c c$ & 0.64 & 0.65 & 0.56 & 0.60 & 0.60 & 0.60 & 0.58 & 0.57 \\
\hline \multirow{2}{*}{$\begin{array}{l}\text { Longitudinal } \\
\text { crack }\end{array}$} & $A v \cdot P r$. & 0.95 & 0.95 & 0.92 & 0.97 & 0.96 & 0.96 & 0.96 & 0.96 \\
\hline & $A u C$ & 1.00 & 0.76 & 0.85 & 0.56 & 0.87 & 0.85 & 0.75 & 0.62 \\
\hline \multirow{2}{*}{$\begin{array}{c}\text { Transverse } \\
\text { crack }\end{array}$} & $A v \cdot P r$. & 1.00 & 0.77 & 0.77 & 0.53 & 0.02 & 0.78 & 0.04 & 0.53 \\
\hline & $A u C$ & 1.00 & 0.97 & 0.97 & 0.96 & 0.19 & 0.98 & 0.69 & 0.87 \\
\hline \multirow{2}{*}{ Patch } & $A v \cdot P r$. & 0.75 & 0.86 & 0.80 & 0.75 & 0.69 & 0.79 & 0.72 & 0.63 \\
\hline & $A u C$ & 0.85 & 0.93 & 0.89 & 0.82 & 0.85 & 0.89 & 0.83 & 0.81 \\
\hline \multirow{2}{*}{ Pothole } & $A v \cdot P r$. & 1.00 & 0.76 & 0.98 & 0.96 & 0.92 & 0.99 & 1.00 & 0.93 \\
\hline & $A u C$ & 1.00 & 0.94 & 0.99 & 0.99 & 0.96 & 0.99 & 1.00 & 0.96 \\
\hline Healthy & $A v \cdot P r$. & 0.97 & 0.99 & 0.98 & 0.98 & 0.98 & 0.98 & 0.96 & 0.97 \\
\hline pavement & $A u C$ & 0.07 & 0.60 & 0.21 & 0.19 & 0.38 & 0.43 & 0.10 & 0.32 \\
\hline
\end{tabular}

793

794

795

796

797

798

799

800

801

802 
803 Table 6 Tested parameters and results of STFs (data captured by PG camera using 5 categories)

\begin{tabular}{|c|c|c|c|c|c|c|c|c|c|c|}
\hline & $\begin{array}{c}\text { Test } \\
1\end{array}$ & $\begin{array}{c}\text { Test } \\
2\end{array}$ & $\begin{array}{c}\text { Test } \\
3\end{array}$ & $\begin{array}{c}\text { Test } \\
4\end{array}$ & $\begin{array}{c}\text { Test } \\
5\end{array}$ & $\begin{array}{c}\text { Test } \\
6\end{array}$ & $\begin{array}{c}\text { Test } \\
7\end{array}$ & $\begin{array}{c}\text { Test } \\
8\end{array}$ \\
\hline & & Box size & 15 & 11 & 9 & 13 & 17 & 11 & 11 & 11 \\
\hline & & $\begin{array}{c}\text { Max tree } \\
\text { depth }\end{array}$ & $\begin{array}{c}10 \& \\
14\end{array}$ & $\begin{array}{c}10 \& \\
14\end{array}$ & $\begin{array}{c}10 \& \\
14\end{array}$ & $\begin{array}{c}10 \& \\
14\end{array}$ & $\begin{array}{c}10 \& \\
14\end{array}$ & $\begin{array}{c}11 \& \\
13\end{array}$ & $\begin{array}{c}12 \& \\
16\end{array}$ & $\begin{array}{c}15 \& \\
16\end{array}$ \\
\hline \multirow{12}{*}{ 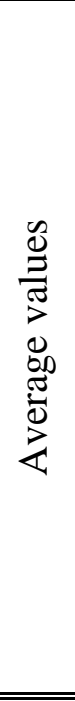 } & & Ov.Acc. & 0.83 & 0.84 & 0.82 & 0.82 & 0.82 & 0.82 & 0.84 & 0.86 \\
\hline & & $A c c$ & 0.74 & 0.76 & 0.74 & 0.72 & 0.76 & 0.74 & 0.74 & 0.72 \\
\hline & \multirow{4}{*}{$\begin{array}{l}\text { Longitudinal } \\
\text { crack } \\
\text { Transverse } \\
\text { crack }\end{array}$} & $A v \cdot P r$. & 0.93 & 0.94 & 0.94 & 0.92 & 0.93 & 0.95 & 0.94 & 0.92 \\
\hline & & & 0.96 & 0.96 & 0.96 & 0.95 & 0.96 & 0.96 & 0.96 & 0.96 \\
\hline & & Av.Pr. & 0.84 & 0.73 & 0.83 & 0.86 & 0.81 & 0.83 & 0.85 & 0.85 \\
\hline & & $A u C$ & 0.95 & 0.94 & 0.97 & 0.93 & 0.94 & 0.93 & 0.94 & 0.94 \\
\hline & \multirow{2}{*}{ Patch } & Av.Pr. & 0.96 & 0.94 & 0.94 & 0.95 & 0.96 & 0.95 & 0.96 & 0.96 \\
\hline & & & 0.94 & 0.92 & 0.93 & 0.93 & 0.92 & 0.91 & 0.95 & 0.95 \\
\hline & \multirow{2}{*}{ Pothole } & Av.Pr. & 0.84 & 0.82 & 0.82 & 0.77 & 0.79 & 0.81 & 0.81 & 0.76 \\
\hline & & $A u C$ & 0.93 & 0.92 & 0.93 & 0.92 & 0.90 & 0.91 & 0.95 & 0.89 \\
\hline & \multirow{2}{*}{$\begin{array}{c}\text { Healthy } \\
\text { pavement }\end{array}$} & $A v \cdot P r$. & 0.97 & 0.97 & 0.97 & 0.98 & 0.98 & 0.92 & 0.98 & 0.96 \\
\hline & & $A u C$ & 0.65 & 0.62 & 0.60 & 0.69 & 0.65 & 0.66 & 0.70 & 0.55 \\
\hline \multirow{12}{*}{ 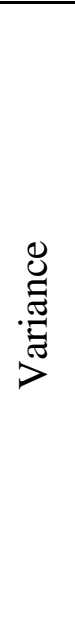 } & & & 0.00 & 0.00 & 0.00 & 0.00 & 0.00 & 0.00 & 0.00 & 0.00 \\
\hline & & & 0.00 & 0.00 & 0.00 & 0.00 & 0.00 & 0.00 & 0.00 & 0.00 \\
\hline & \multirow{2}{*}{ Longitudinal } & $A v \cdot P r$ & 0.00 & 0.00 & 0.00 & 0.00 & 0.00 & 0.00 & 0.00 & 0.00 \\
\hline & & & 0.00 & 0.00 & 0.00 & 0.00 & 0.00 & 0.00 & 0.00 & 0.00 \\
\hline & \multirow{2}{*}{$\begin{array}{l}\text { Transverse } \\
\text { crack }\end{array}$} & Av.Pr. & 0.00 & 0.01 & 0.01 & 0.01 & 0.02 & 0.02 & 0.01 & 0.01 \\
\hline & & & 0.00 & 0.00 & 0.00 & 0.00 & 0.00 & 0.00 & 0.00 & 0.00 \\
\hline & \multirow{2}{*}{ Patc } & Av.Pr. & 0.00 & 0.00 & 0.00 & 0.00 & 0.00 & 0.00 & 0.00 & 0.00 \\
\hline & & & 0.00 & 0.00 & 0.00 & 0.00 & 0.00 & 0.00 & 0.00 & 0.00 \\
\hline & \multirow{2}{*}{ Potho } & $A v \cdot P r$. & 0.00 & 0.01 & 0.00 & 0.01 & 0.01 & 0.01 & 0.00 & 0.01 \\
\hline & & & 0.00 & 0.00 & 0.00 & 0.00 & 0.00 & 0.00 & 0.00 & 0.00 \\
\hline & & Av.Pr. & 0.00 & 0.00 & 0.00 & 0.00 & 0.00 & 0.01 & 0.00 & 0.00 \\
\hline & pavement & $A u C$ & 0.02 & 0.01 & 0.03 & 0.01 & 0.01 & 0.03 & 0.02 & 0.02 \\
\hline
\end{tabular}

804

805

806

807

808

809

810

811 
812 Table 7 Tested parameters and results of STFs (data captured by PG camera using 5 categories 813 and myROI)

\begin{tabular}{|c|c|c|c|c|c|c|c|c|c|c|}
\hline & $\begin{array}{c}\text { Test } \\
1\end{array}$ & $\begin{array}{c}\text { Test } \\
2\end{array}$ & $\begin{array}{c}\text { Test } \\
3\end{array}$ & $\begin{array}{c}\text { Test } \\
4\end{array}$ & $\begin{array}{c}\text { Test } \\
5\end{array}$ & $\begin{array}{c}\text { Test } \\
6\end{array}$ & $\begin{array}{c}\text { Test } \\
7\end{array}$ & $\begin{array}{c}\text { Test } \\
8\end{array}$ \\
\hline & & Box size & 15 & 13 & 11 & 17 & 9 & 9 & 9 & 9 \\
\hline & & Max tree & $10 \&$ & $10 \&$ & $10 \&$ & $10 \&$ & $10 \&$ & $11 \&$ & $10 \&$ & $12 \&$ \\
\hline \multirow{12}{*}{ 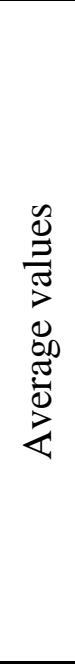 } & & Ov.Acc. & 0.83 & 0.83 & 0.83 & 0.83 & 0.83 & 0.83 & 0.85 & $\begin{array}{l}0.84 \\
\end{array}$ \\
\hline & & $A v \cdot A c c$ & 0.75 & 0.73 & 0.74 & 0.74 & 0.74 & 0.75 & 0.74 & 0.73 \\
\hline & \multirow{4}{*}{$\begin{array}{l}\text { Longitudinal } \\
\text { crack } \\
\text { Transverse } \\
\text { crack }\end{array}$} & $A v \cdot P r$. & 0.92 & 0.91 & 0.92 & 0.90 & 0.92 & 0.91 & 0.92 & 0.93 \\
\hline & & $A u C$ & 0.95 & 0.94 & 0.96 & 0.94 & 0.96 & 0.96 & 0.96 & 0.96 \\
\hline & & $A v \cdot P r$. & 0.89 & 0.92 & 0.83 & 0.83 & 0.81 & 0.82 & 0.83 & 0.87 \\
\hline & & $A u C$ & 0.95 & 0.98 & 0.94 & 0.95 & 0.93 & 0.89 & 0.95 & 0.95 \\
\hline & \multirow{2}{*}{ Patch } & Av.Pr. & 0.88 & 0.90 & 0.88 & 0.88 & 0.91 & 0.91 & 0.89 & 0.88 \\
\hline & & $A u C$ & 0.89 & 0.89 & 0.88 & 0.87 & 0.90 & 0.90 & 0.88 & 0.87 \\
\hline & \multirow{2}{*}{ Pothole } & Av.Pr. & 0.71 & 0.71 & 0.66 & 0.66 & 0.62 & 0.62 & 0.68 & 0.56 \\
\hline & & $A u C$ & 0.90 & 0.92 & 0.83 & 0.93 & 0.90 & 0.89 & 0.93 & 0.87 \\
\hline & \multirow{2}{*}{$\begin{array}{c}\text { Healthy } \\
\text { pavement }\end{array}$} & Av.Pr. & 0.96 & 0.87 & 0.96 & 0.98 & 0.96 & 0.96 & 0.97 & 0.97 \\
\hline & & $A u C$ & 0.67 & 0.62 & 0.59 & 0.66 & 0.54 & 0.48 & 0.62 & 0.66 \\
\hline \multirow{12}{*}{ 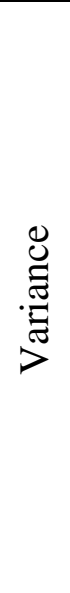 } & & $O v \cdot A c$ & 0.00 & 0.00 & 0.00 & 0.00 & 0.00 & 0.00 & 0.00 & 0.00 \\
\hline & & $A v \cdot A c$ & 0.00 & 0.00 & 0.00 & 0.00 & 0.00 & 0.00 & 0.00 & 0.00 \\
\hline & \multirow{4}{*}{$\begin{array}{l}\text { Longitudinal } \\
\text { crack } \\
\text { Transverse } \\
\text { crack }\end{array}$} & Av.Pr. & 0.00 & 0.00 & 0.00 & 0.00 & 0.00 & 0.00 & 0.00 & 0.00 \\
\hline & & $A u$ & 0.00 & 0.00 & 0.00 & 0.00 & 0.00 & 0.00 & 0.00 & 0.00 \\
\hline & & $A v \cdot P r$. & 0.00 & 0.00 & 0.00 & 0.00 & 0.00 & 0.00 & 0.00 & 0.00 \\
\hline & & & 0.00 & 0.00 & 0.00 & 0.00 & 0.00 & 0.01 & 0.00 & 0.00 \\
\hline & \multirow{2}{*}{ Patch } & $A v \cdot P r$. & 0.00 & 0.00 & 0.00 & 0.00 & 0.00 & 0.00 & 0.00 & 0.00 \\
\hline & & & 0.00 & 0.00 & 0.00 & 0.00 & 0.00 & 0.00 & 0.00 & 0.00 \\
\hline & \multirow{2}{*}{ Pothole } & $A v \cdot P r$. & 0.02 & 0.00 & 0.02 & 0.00 & 0.00 & 0.00 & 0.00 & 0.01 \\
\hline & & & 0.01 & 0.00 & 0.03 & 0.00 & 0.00 & 0.00 & 0.00 & 0.00 \\
\hline & & $A v . P r$. & 0.00 & 0.03 & 0.00 & 0.00 & 0.00 & 0.00 & 0.00 & 0.00 \\
\hline & & $A$ & 0.01 & 0.03 & 0.04 & 0.01 & 0.03 & 0.03 & 0.02 & 0.01 \\
\hline
\end{tabular}

814

815

816 
818 Table 8 Confusion matrix for 2D segmentation of defects (data captured with HP camera using 4 819 categories - results from test 1)

\begin{tabular}{l|rrrr}
\hline & $\begin{array}{c}\text { Longitudinal } \\
\text { crack }\end{array}$ & $\begin{array}{c}\text { Transverse } \\
\text { crack }\end{array}$ & Patch & Pothole \\
\hline $\begin{array}{l}\text { Longitudinal } \\
\text { crack }\end{array}$ & 0.80 & 0.00 & 0.17 & 0.00 \\
$\begin{array}{l}\text { Transverse } \\
\text { crack }\end{array}$ & 0.67 & 0.02 & 0.12 & 0.00 \\
Patch & 0.21 & 0.00 & 0.78 & 0.00 \\
Pothole & 0.06 & 0.00 & 0.20 & 0.74 \\
\hline
\end{tabular}

820

821 Table 9 Confusion matrix for 2D segmentation of defects (data captured with HP camera using 5 822 categories - results from test 6)

\begin{tabular}{l|rrrrr}
\hline & $\begin{array}{c}\text { Longitudinal } \\
\text { crack }\end{array}$ & $\begin{array}{c}\text { Transverse } \\
\text { crack }\end{array}$ & Patch & Pothole & $\begin{array}{c}\text { Healthy } \\
\text { pavement }\end{array}$ \\
\hline $\begin{array}{l}\text { Longitudinal } \\
\text { crack }\end{array}$ & 0.28 & 0.01 & 0.05 & 0.00 & 0.66 \\
$\begin{array}{l}\text { Transverse } \\
\text { crack }\end{array}$ & 0.00 & 0.71 & 0.00 & 0.05 & 0.24 \\
$\begin{array}{l}\text { Patch } \\
\begin{array}{l}\text { Pothole } \\
\text { Healthy } \\
\text { pavement }\end{array}\end{array}$ \\
\hline
\end{tabular}

823

824 Table 10 Confusion matrix for 2D segmentation of defects (data captured with PG camera using 825 5 categories - results from test 8 )

\begin{tabular}{l|rrrrr}
\hline & $\begin{array}{c}\text { Longitudinal } \\
\text { crack }\end{array}$ & $\begin{array}{c}\text { Transverse } \\
\text { crack }\end{array}$ & Patch & Pothole & $\begin{array}{c}\text { Healthy } \\
\text { pavement }\end{array}$ \\
\hline $\begin{array}{l}\text { Longitudinal } \\
\text { crack }\end{array}$ & 0.69 & 0.01 & 0.01 & 0.00 & 0.29 \\
$\begin{array}{l}\text { Transverse } \\
\text { crack }\end{array}$ & 0.02 & 0.63 & 0.01 & 0.00 & 0.34 \\
$\begin{array}{l}\text { Patch } \\
\text { Pothole }\end{array}$ & 0.02 & 0.01 & 0.61 & 0.00 & 0.36 \\
$\begin{array}{l}\text { Healthy } \\
\text { pavement }\end{array}$ & 0.06 & 0.00 & 0.03 & 0.78 & 0.13 \\
\hline
\end{tabular}


827 Table 11 Confusion matrix for 2D segmentation of defects (data captured with PG camera using 828 5 categories and myROI - results from test 7)

\begin{tabular}{l|rrrrr}
\hline & $\begin{array}{c}\text { Longitudinal } \\
\text { crack }\end{array}$ & $\begin{array}{c}\text { Transverse } \\
\text { crack }\end{array}$ & Patch & Pothole & $\begin{array}{c}\text { Healthy } \\
\text { pavement }\end{array}$ \\
\hline $\begin{array}{l}\text { Longitudinal } \\
\text { crack }\end{array}$ & 0.75 & 0.01 & 0.02 & 0.00 & 0.22 \\
$\begin{array}{l}\text { Transverse } \\
\text { crack }\end{array}$ & 0.02 & 0.63 & 0.01 & 0.00 & 0.34 \\
$\begin{array}{l}\text { Patch } \\
\begin{array}{l}\text { Pothole } \\
\text { Healthy } \\
\text { pavement }\end{array}\end{array} \quad 0.02$ & 0.01 & 0.63 & 0.00 & 0.34 \\
\hline
\end{tabular}

829 